\title{
Moon orientation on moonless nights
}

\author{
ALBERTO UGOLINI*, CARLO CASTELLINI† \& LUCA MERCATELLI† \\ *Dipartimento di Biologia Animale e Genetica, Università di Firenze \\ $\dagger$ Istituto Nazionale di Ottica Applicata - CNR \\ (Received 1 March 2006; initial acceptance 31 March 2006; \\ final acceptance 8 May 2006; published online 19 December 2006; MS. number: 8865R)
}

\begin{abstract}
The sandhopper Talitrus saltator is known to use sun and moon compasses to return to the band of wet sand on a beach. The two compass systems are based on separate chronometric mechanisms that compensate for the azimuthal movement of the two astronomical cues. The aim of our research was to test whether the sandhopper's time-compensating mechanism for lunar compass orientation continues to work during the new moon phase (i.e. when the moon is not visible). Our tests were carried out in a confined environment under the natural sky and in the laboratory under artificial light, in both the full and new moon phases. Sandhoppers released in sea water headed towards the expected land direction of their home beach using the natural or artificial moon as a compass cue independently of the moon's natural phase, including the new moon phase. The sandhoppers' chronometric mechanism that compensates for the moon's azimuthal motion thus works continuously, even during the phase when the actual moon is never visible. This could be based on spatiotemporal interpolation between visible moon positions.
\end{abstract}

(c) 2006 The Association for the Study of Animal Behaviour. Published by Elsevier Ltd. All rights reserved.

Keywords: chronometric mechanisms; moon compass; orientation; sandhopper; Talitrus saltator

The study of biological rhythms and the study of orientation mechanisms are two classic fields of research in animal behaviour, even though their mutual relationship has rarely been considered (Ugolini 2003). In fact, although synodic monthly and fortnightly rhythms are well known (Palmer 1995), none has been shown to be related to chronometric aspects of compass orientation.

The sandhopper Talitrus saltator, like other species of sandhoppers and beach flies, has been a good biological model for studies on compass mechanisms since the early 1950s (Pardi \& Papi 1952). Despite its lack of a circatidal activity rhythm (Williams 1979), T. saltator is among the few arthropods in which a moon compass has been demonstrated: sandhoppers use the moon and sun as compass cues to steer the correct and shortest route along the sealand axis of their home beach (Papi \& Pardi 1953; Pardi \& Ercolini 1986; Ugolini et al. 1999a, 2002a, 2003; Ugolini 2003).

Correspondence: A. Ugolini, Dipartimento di Biologia Animale e Genetica, Università di Firenze, Via Romana 1750125 Firenze, Italy (email: ugolini_alb@dbag.unifi.it).C. Castellini and L. Mercatelli are at the Istituto Nazionale di Ottica Applicata - CNR, Largo E. Fermi 6, 50125 Firenze, Italy.
During the day, sandhoppers remain under the wet sand in temporary refuges that protect them from predators and dehydration. However, natural (e.g. changes in the sea, periodic foraging migrations) or artificial disturbances (e.g. human trampling) might force the sandhoppers to leave their refuges under the sand, exposing them to the risk of death. The ability of $T$. saltator to use astronomical cues to return to the band of wet sand of the beach following the shortest path, i.e. the sea-land axis, has been studied frequently since the pioneering paper of Pardi \& Papi (1952). This ability (i.e. zonal recovery) is shared by many arthropods of different taxa living in the same or similar habitats (ecotonal environments, see Campan 1997). This zonal recovery is mainly based on the ability to compensate chronometrically for the azimuthal variation of the sun and moon to maintain (theoretically constant) the sea-land direction of orientation throughout the day and night (reviewed in Pardi \& Ercolini 1986; Ugolini et al. 2002a; Ugolini 2003).

The moon compass coexists with a sun compass, but the two chronometric mechanisms are independent of each other (Ugolini et al. 1999b). The use of the moon as an orienting factor, the existence of a moon compass and of separate chronometric mechanisms for sun and moon compensation, and the use of an artificial light source to 
reproduce good moon orientation have already been demonstrated in sandhoppers (Pardi \& Papi 1952; Pardi \& Ercolini 1986; Ugolini et al. 1999a, 2002a, 2003, 2005; Ugolini 2003). The aim of our research was to test whether the sandhopper's time-compensating mechanism for lunar compass orientation continues to work when the moon is invisible (during the new moon phase).

\section{METHODS}

We carried out experiments on adult T. saltator collected on a beach of southern Tuscany, Albegna, Italy (landward direction of the sea-land axis $=88^{\circ}$ ). All testing was done near Florence in spring and summer 2003 and 2005. The sandhoppers were kept in the laboratory for 7-14 days after capture under artificial light in containers with wet sand and food. The duration and phase of the artificial light:dark cycle matched the current natural photoperiod. The temperature was subject to natural variations. Recordings of freely chosen compass directions were made under the following two conditions.

\section{Releases Under the Natural Sky}

Groups of about five sandhoppers were released in a transparent Plexiglas bowl (diameter $=19 \mathrm{~cm}$ ) with $1-$ $2 \mathrm{~cm}$ of sea water. Sea water induces sandhoppers to orient in the landward direction of their home beach within a few tens of seconds. We placed the bowl horizontally on a transparent plate so that the sandhoppers could be observed from below. The bowl and plate were mounted on a tripod and surrounded by a cylindrical screen 1$3 \mathrm{~cm}$ higher than the water level, which blocked the sandhoppers' view of the surrounding landscape. To prevent the sandhoppers using the natural magnetic field as a compass cue to maintain a constant direction even in the absence of visual reference points (Arendse 1978), we equipped the device with a pair of suitably powered Helmholtz coils (diameter $=64 \mathrm{~cm}$, distance $=35 \mathrm{~cm}$ ) to cancel the horizontal component of the natural magnetic field (see Ugolini 2001 for further details). Releases were carried out under a full moon (lunar phase from 89 to 96\%) and on moonless nights (new moon phase). In both cases, an artificial moon (an electric torch) was projected on to the sandhoppers from a distance of about $2 \mathrm{~m}$ (light intensity $5 \mu \mathrm{W} / \mathrm{cm}^{2}$ ); when full, the natural moon was screened out. We determined a single direction for each individual about 2 min after adding it to the bowl. The directions were measured from freeze-frame images recorded by an infrared-sensitive video camera placed below the bowl.

\section{Releases in the Laboratory}

The Plexiglas bowl was placed in an apparatus (a white Plexiglas dome equipped with two fibre-optic bundles; Fig. 1a) representing a scenario with artificial moon and sky, which allows orientation similar to that obtained under the natural moon (Ugolini et al. 1998, 2005) despite radiometric and spectral differences with respect to the
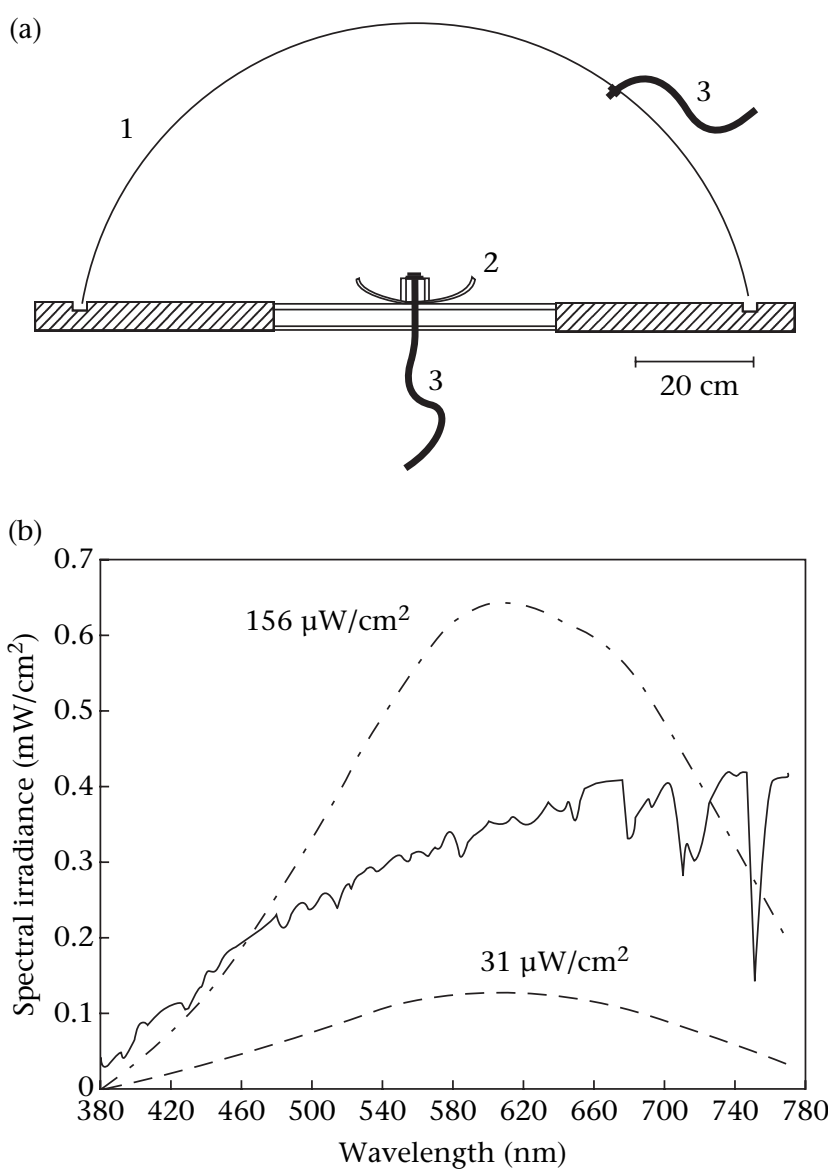

Figure 1. (a) Apparatus used for moon orientation in the laboratory experiments. (b) The spectral distribution of the natural (solid line) and artificial moon at the two levels of irradiance used (the values are reported near the respective dashed lines). In (a), the dome (1), the circular bowl in which the sandhoppers were released (2) and the two fibre-optic bundles (3) are shown.

natural moon (irradiance: natural moon: $130-140 \mu \mathrm{W} /$ $\mathrm{cm}^{2}$; artificial moon: $31 \mu \mathrm{W} / \mathrm{cm}^{2}$ and $156 \mu \mathrm{W} / \mathrm{cm}^{2}$; Fig. 1b). Spectral and radiometric measurements of the natural and artificial moon were made with a Minolta CS1000 spectroradiometer (Minolta, Milan, Italy) and a UDT Instruments S370 Graseby radiometer (radiometric head no. 247, UDT Instruments, Baltimore, MD, U.S.A.). Directional data were analysed by the methods of circular statistics (Batschelet 1981). For each distribution, we calculated the mean angle and the length of the mean resultant vector. The $V$ test was used to assess the nonuniformity of circular distributions. Confidence intervals of the mean angles were also calculated $(P=0.01)$.

\section{RESULTS}

\section{Releases Under the Natural Sky}

Releases carried out under the natural sky in the full moon phase without the horizontal component of the natural magnetic field resulted in good sandhopper orientation in the expected direction (i.e. the landward 
direction of the sea-land axis of the home beach). This was true both with a view of the natural moon (mean angle confidence interval $=52^{\circ}-104^{\circ}$; Fig. 2 a) and with a view of the artificial moon (the electric torch, with the natural full moon screened; Fig. 2b) projected on to the sandhoppers from an azimuth $90^{\circ}$ to the natural moon's azimuth. The difference between the mean vector direction and the new expected direction was $0^{\circ}$ (mean angle confidence interval $=142^{\circ}-214^{\circ}$; Fig. $2 \mathrm{~b}$ ). Similar results
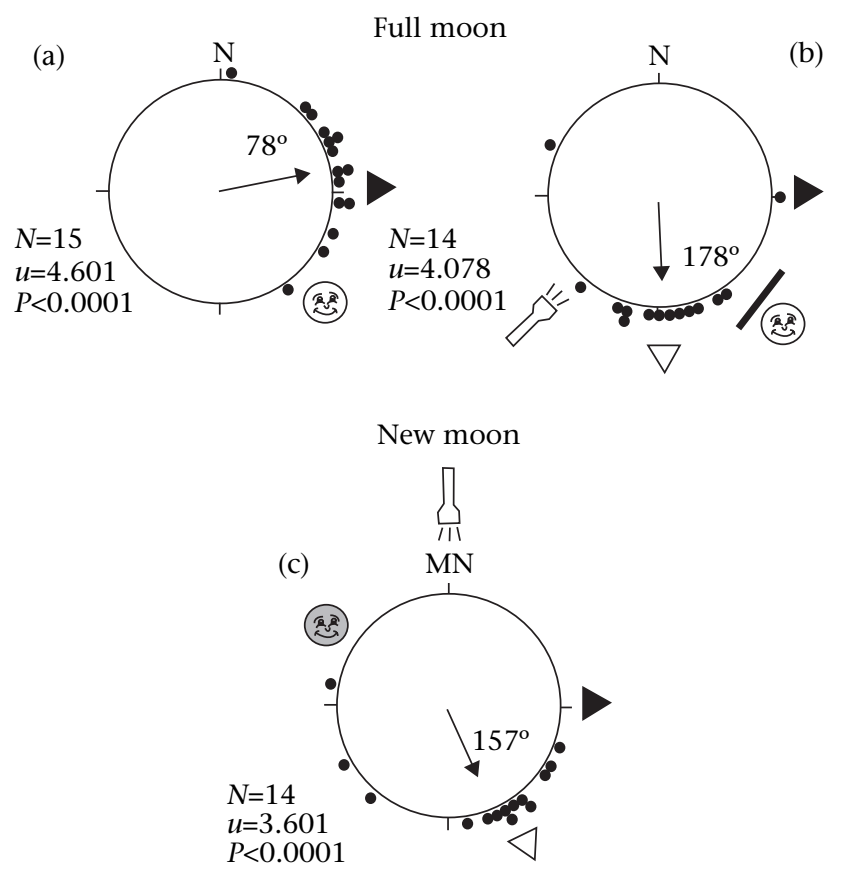

(d)
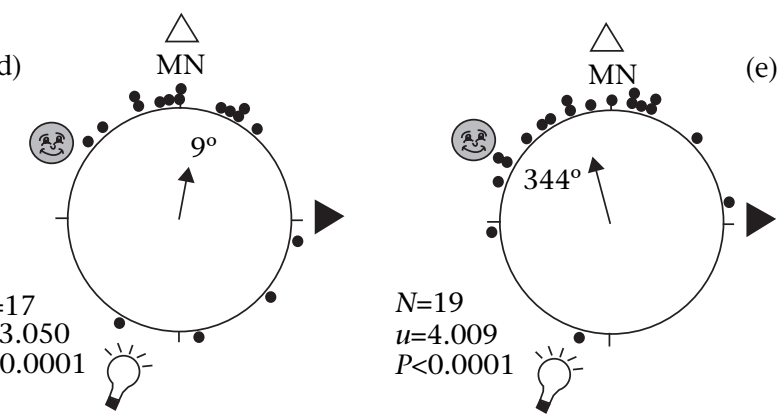

Figure 2. Moon orientation by sandhoppers on moonless nights. (a) Orientation under the natural full moon; (b, c), experiments under the light of an electric torch. (b) The natural moon was screened out. (c) New moon phase. $>$ : Land of the home beach; $\Delta$ : landward direction indicated by the artificial moon. $(d, e)$ Experiments in the new moon phase carried out in the laboratory under the Plexiglas dome (Fig. 1a). The irradiance of the artificial moon was $31 \mu \mathrm{W} /$ $\mathrm{cm}^{2}$ in (d) and $156 \mu \mathrm{W} / \mathrm{cm}^{2}$ in (e). See Fig. $1 \mathrm{~b}$ for spectral distributions. The arrow inside each distribution represents the mean vector direction and length (length ranges from $0=$ disorientation to the radius of the circle $=1$, perfect orientation); : individual directions. $\mathrm{N}$ : Geographical north (zeroed magnetic field); MN: magnetic north (natural magnetic field). The lunar azimuth at the time of release is represented outside each distribution (shaded moon, new moon phase). The azimuth of the artificial moon is represented by (b, $c$ ) a torch or (d, e) a lamp. Sample size, $N$, the $V$ test value, $u$, with the probability level, $P$, are also given. were obtained in tests carried out in the new moon phase (Fig. 2c): the mean vector pointed towards the new direction (indicated by the white triangle), based on a view of the electric torch (difference $=11^{\circ}$; mean angle confidence interval $=118^{\circ}-196^{\circ}$ ).

\section{Releases in the Laboratory}

Releases carried out in the laboratory in the new moon phase under artificial conditions of moonlight and sky (Plexiglas dome; Fig. 2d, e) produced similar results despite differences in the spectral distribution and irradiance (Fig. 1b). There was good orientation in the landward direction expected (maximum $13^{\circ}$ of difference) if the sandhoppers were to use the artificial illumination as the moon even though the moon was not present in the sky (mean angle confidence interval $=316^{\circ}-62^{\circ}$, Fig. $2 \mathrm{~d}$; $307^{\circ}-23^{\circ}$, Fig. $\left.2 \mathrm{e}\right)$.

\section{DISCUSSION}

Our experiments unambiguously showed that sandhoppers were able to use the moon compass for ecologically efficient direction finding (the sea-land axis of the beach) even when the moon was not visible in the sky, that is, when the moon could not be used as an orienting factor during the lunar month. In other words, the sandhoppers 'knew' the azimuth of the naturally invisible new moon and, at a given hour of the night, were able to assume the correct angle: reference direction-sandhopper-(new) moon. Therefore, the chronometric mechanism of the moon compass operates continuously throughout the lunar month, independently of the lunar phase. This raises at least three interesting questions.

(1) Why are sandhoppers able to use an orienting cue even when it is not visible? A continuously running, lunar, spatiotemporal control mechanism is undoubtedly simpler to implement than a more complex mechanism that is unnecessarily turned off with precise lunar rhythmicity. In bees, the control mechanism underlying the sun compass orientation keeps running throughout the day and night (Lindauer 1957).

(2) How do sandhoppers 'know' the azimuth of the moon during the new moon phase? At present, we can only speculate on this matter. However, while bees and ants are known to have an internal mechanism (i.e. the ephemerids function, Wehner \& Mueller 1993) that describes the sun's path in the sky, allowing for sun compensation when they are prevented from seeing the sun for some time (e.g. see Gould 1980; Wehner \& Lanfranconi 1981), sandhoppers do not seem to have a similar system. Sandhoppers appear to compensate for solar azimuthal variation by the sun compass chronometric mechanism running at constant speed (Ugolini et al. 2002b); however, the lunar compensation is far more complex than the solar compensation. During the lunar month, the moon is not always present, it never rises at the same time and it does not have the same shape. Therefore, it is difficult to imagine that sandhoppers possess a mechanism that tracks the moon for an entire synodic month. Since the 
sandhoppers in our study could not acquire any information about the moon's azimuth during the new moon phase (they were kept in the laboratory for 7-14 days under artificial illumination and without any possibility of seeing the natural sky), we can hypothesize a spatiotemporal interpolation between the visible phases of the moon.

(3) Do sandhoppers use the natural moon and an artificial light source in the same way for orientation at night, despite the strong differences in light intensity and spectral composition? Our results, and previous findings, clearly show that an artificial light source is used at night as if it were the real moon; furthermore, this is largely independent of the light source's intensity and spectral composition or the phase of the real moon (Ugolini et al. 2002a, 2005; Ugolini 2003). In our experiments, the artificial light source was never mistaken for the sun, since sun compensation at night is based on a mechanism that involves the sun returning to the east after sunset and passing from the south (Talitrus model) instead of from the north (Apis model; Pardi \& Ercolini 1986; Ugolini et al. $2002 \mathrm{~b}$ ). If the sandhoppers were to identify the artificial light source as the 'sun at night', their directional choice should deviate from the sea-land direction expected for an orientation based on the sun during the day and the moon at night. Therefore, the only possible explanation for the good agreement observed in our experiments between the mean angle of orientation and the expected landward direction is the use of the artificial light source as the natural moon.

\section{Acknowledgments}

We thank Professor R. Jander, University of Kansas, and Professor K.J. Lohmann, University of North Carolina, for their critical reading of the manuscript and for their useful comments and stimulating discussion. Financial support was provided by the Università di Firenze (local funds, ex$60 \%)$.

\section{References}

Arendse, M. C. 1978. Magnetic field detection is distinct from light detection in the invertebrates Tenebrio and Talitrus. Nature, 274, 358-362.

Batschelet, E. 1981. Circular Statistics in Biology. London: Academic Press.

Campan, R. 1997. Tactic components in orientation. In: Orientation and Communication in Arthropods (Ed. by M. Lehrer), pp. 1-40. Basel: Birkhäuser Verlag.
Gould, J. L. 1980. Sun compensation by bees. Science, 207, 545547.

Lindauer, M. 1957. Sonnenorientierung der Bienen unter der Äquatorsonne und zur Nachtzeit. Naturwissenschaften, 44, 1-6.

Palmer, J. D. 1995. The Biological Rhythms and Clocks of Intertidal Animals. Oxford: Oxford University Press.

Papi, F. \& Pardi, L. 1953. Ricerche sull'orientamento di Talitrus saltator (Montagu) (Crustacea-Amphipoda) II. Sui fattori che regolano la variazione dell'angolo di orientamento nel corso del giorno. L'orientamento di notte. L'orientamento diurno di altre popolazioni. Zeitschrift für Vergleichende Physiologie, 35, 490-518.

Pardi, L. \& Ercolini, A. 1986. Zonal recovery mechanism in talitrid crustaceans. Bolettino di Zooogia, 53, 139-160.

Pardi, L. \& Papi, F. 1952. Die Sonne als Kompass bei Talitrus saltator. Naturwissenschaften, 39, 262-263.

Ugolini, A. 2001. Relationship between compass systems of orientation in equatorial sandhoppers. Animal Behaviour, 62, 193-199.

Ugolini, A. 2003. Activity rhythms and orientation in sandhoppers (Crustacea, Amphipoda). Frontiers in Bioscience, S8, 722-732.

Ugolini, A., Tiribilli, B. \& Castellini, C. 1998. Artificial light and sun compass orientation in the sandhopper Talitrus saltator (Crustacea-Amphipoda). Journal of Comparative Physiology A, 182, 43-50.

Ugolini, A., Melis, C. \& Innocenti, R. 1999a. Moon orientation in adult and young sandhoppers. Journal of Comparative Physiology A, 184, 9-12.

Ugolini, A., Melis, C., Innocenti, R., Tiribilli, B. \& Castellini, C. $1999 \mathrm{~b}$. Moon and sun compasses in sandhoppers rely on two separate chronometric mechanisms. Proceedings of the Royal Society of London, Series B, 266, 749-752.

Ugolini, A., Melis, C., Tiribilli, B. \& Castellini, C. 2002a. The sun, the moon, and the sandhopper. In: Crustacean Experimental Systems in Neurobiology (Ed. by K. Wiese), pp. 247-260. Berlin: Springer Verlag.

Ugolini, A., Tiribilli, B. \& Boddi, V. 2002b. The sun compass of the sandhopper Talitrus saltator. The speed of the chronometric mechanism depends on the hours of light. Journal of Experimental Biology, 205, 3225-3230.

Ugolini, A., Fantini, T. \& Innocenti, R. 2003. Orientation at night: an innate moon compass in sandhoppers (Amphipoda: Talitridae). Proceedings of the Royal Society of London, Series B, 270, 279-281.

Ugolini, A., Boddi, V., Mercatelli, L. \& Castellini, C. 2005. Moon orientation in adult and young sandhoppers under artificial light. Proceedings of the Royal Society of London, Series B, 272, 21892194.

Wehner, R. \& Lanfranconi, B. 1981. What do the ants know about the rotation of the sky? Nature, 293, 731-733.

Wehner, R. \& Mueller, M. 1993. How do ants acquire their celestial ephemerids function? Naturwissenschaften, 80, 331-333.

Williams, J. A. 1979. A semi-lunar rhythm of locomotor activity and moult synchrony in the sand beach amphipod Talitrus saltator. In: Cyclic Phenomena in Marine Plants and Animals (Ed. by E. Naylor \& R. G. Hartnoll), pp. 407-414. Oxford: Pergamon Press. 